\title{
Response of Commercially Developed Soybean Cultivars and the Ancestral Soybean Lines to Fusarium solani f. sp. glycines
}

\author{
D. S. Mueller, Department of Crop Sciences, R. L. Nelson and G. L. Hartman, United States Department of \\ Agriculture-Agricultural Research Service, Soybean/Maize Germplasm, Pathology, and Genetics Research Unit and \\ Department of Crop Sciences, and W. L. Pedersen, Department of Crop Sciences, University of Illinois, Urbana \\ 61801
}

\begin{abstract}
Mueller, D. S., Nelson, R. L., Hartman, G. L., and Pedersen, W. L. 2003. Response of commercially developed soybean cultivars and the ancestral soybean lines to Fusarium solani f. sp. glycines. Plant Dis. 87:827-831.

Sudden death syndrome, caused by Fusarium solani f. sp. glycines, has caused severe damage to soybean production in recent years. One way to control sudden death syndrome is with resistant cultivars. Over a 3-year period, 2,335 publicly and privately developed soybean entries were inoculated and evaluated for their response to $F$. solani f. sp. glycines under greenhouse conditions. The entries were compared with the susceptible check, Great Lakes 3302 (GL3302), and the moderately resistant checks, plant introductions (PIs) 520733 and 567374. Thirty-eight entries were identified with moderate levels of resistance. Based on foliar ratings, there were no differences $(P<0.05)$ between the Roundup Ready and conventional cultivars. In all, 90 ancestral lines that represent $99 \%$ of the genes in modern U.S. cultivars and 55 lines found in the pedigrees of public cultivars reported to have some resistance were evaluated for their response to $F$. solani f. sp. glycines. Nine ancestral lines (Aoda, Kim, Jackson, Sioux, Mammoth Yellow, T117, PI 171450, PI 54615-1, and PI 71506) and 12 cultivars or experimental lines (Ina, D833349, LN98-4340, LN83-2356, Hartwig, Harosoy, Bedford, Merit, Cutler, Calland, Hill, and Evans) had disease ratings not significantly different $(P<0.05)$ from PI 520733 or PI 567374. PI 54610, a putative ancestral line, also was found to be moderately resistant.
\end{abstract}

Sudden death syndrome (SDS) of soybean (Glycine max (L.) Merr.) is caused by the soilborne fungus Fusarium solani (Mart.) Sacc. f. sp. glycines (16) and has been identified in most soybean-producing regions of the United States $(6,16,26)$. Disease symptoms include mottling, interveinal chlorosis, and necrosis on the upper leaves at flowering, and also root rot, vascular discoloration of stems, defoliation, and pod abortion (16). From 1996 to 1998, SDS was listed as one of the most important diseases in the United States (25). A feature article (16) provided a thorough review of the history of the disease, its symptomology, and research on the causal organism.

\section{Corresponding author: W. L. Pedersen}

E-mail: wpederse@uiuc.edu

Trade and manufacturers' names are necessary to report factually on available data; however, the USDA neither guarantees nor warrants the standard of the product, and the use of the name by the USDA implies no approval of the product to the exclusion of others that may also be suitable.

Salaries and research support provided in part by the Illinois Soybean Program Operating Board (ISPOB).

Accepted for publication 7 February 2003.

Publication no. D-2003-0428-02R

(C) 2003 The American Phytopathological Society
Soybean cultivars and lines that exhibit various levels of resistance to $F$. solani $\mathrm{f}$. sp. glycines have been reported $(9,11-$ $13,17,18,23)$. Several studies have evaluated commercial cultivars for resistance using a limited number of isolates $(12,13,18,19,23)$. In addition, a number of reports have been published that provide data on sources of resistance in soybean plant introductions (PIs; 5,14). However, very few commercial cultivars are marketed as having high levels of resistance to $F$. solani $\mathrm{f}$. sp. glycines.

Different inoculation methods have been reported for evaluating soybean resistance to $F$. solani f. sp. glycines (4,5,9$11,13,14,24)$. In a screen of more than 6,000 PIs (14), a greenhouse technique previously described (5) was used to identify approximately $1 \%$ of the soybean lines with the highest levels of resistance. In a comparison of field and greenhouse results, a positive correlation between foliar ratings was reported (24).

The objectives of this study were to evaluate U.S. soybean cultivars (conventional and Roundup Ready) to identify sources of resistance that could be used immediately by growers and soybean breeders to manage SDS, and to evaluate 90 ancestral lines of U.S. cultivars and 55 lines found in the pedigrees of public cultivars reported to have some resistance to $F$. solani f. sp. glycines to identify the source or sources of resistance to SDS in U.S. cultivars.

\section{MATERIALS AND METHODS}

Soybean entries. Three separate experiments were designed using soybean cultivars and advanced breeding lines, ancestral lines, and lines in the pedigrees of public cultivars reported to be moderately resistant (MR) to SDS. Soybean cultivars and breeding lines (maturity groups I through V) were obtained from the University of Illinois Variety Testing Program and Southern Illinois University Sudden Death Syndrome Testing Program in 1999, 2000, and 2001. Approximately $1,000,670$, and 665 entries were screened in the greenhouse during 1999, 2000, and 2001, respectively, from these sources Ninety ancestral soybean lines (maturity group range 000 to $\mathrm{X}$ ), representing approximately $99 \%$ of the genes in modern North American soybean cultivars (3), were obtained from the United States Department of Agriculture (USDA) Soybean Germplasm Collection, Urbana, IL. Previous studies identified Bell (5), Burlison (15), D83-3349 (7,21), Forrest (8), Ina (15), Jack (10), LN 83-2356 (15), LN 927369 (15), LN 98-4340 (15), and Ripley (22) as MR. Using the USDA Germplasm Resources Information Network (GRIN), 55 extant lines were identified in the pedigrees of these MR lines.

Inoculum increase. Inoculum of $F$. solani f. sp. glycines was prepared by soaking $200 \mathrm{~cm}^{3}$ of sorghum grain in distilled water in a 1-liter Erlenmeyer flask overnight (14). Excess water was drained and the grain was autoclaved for $60 \mathrm{~min}$ at $121^{\circ} \mathrm{C}$ on consecutive days and allowed to cool. After cooling, 10 plugs, $6 \mathrm{~mm}$ in diameter, containing mycelia of $F$. solani $\mathrm{f}$. sp. glycines isolate Mont-1 (4) on water agar, were added to the flask. The flask was shaken daily and incubated at $24^{\circ} \mathrm{C}$ under continuous fluorescent light $(60 \mu \mathrm{E}$ $\mathrm{m}^{-2} \mathrm{~s}^{-1}$ ). After 10 days of growth, inoculum was stored at $4^{\circ} \mathrm{C}$.

Plant inoculations. A greenhouse steam-treated soil mix (4 liters; 1:1, sand:soil) was placed in galvanized flats ( 50 by 35 by $10 \mathrm{~cm}$ ). A template was used to make seven furrows $2 \mathrm{~cm}$ deep and 35 $\mathrm{cm}$ long, and $10 \mathrm{~cm}^{3}$ of infested sorghum seed was distributed evenly in each furrow. The inoculum then was covered with $2 \mathrm{~cm}$ 
of soil and the template was reapplied to make a furrow $0.5 \mathrm{~cm}$ deep directly over the inoculum. Five seed were added to each furrow and covered with another $2 \mathrm{~cm}$ of soil. Plants then were placed on a greenhouse bench and grown under a 16-h photoperiod. The photosynthetically active radiation was $434 \mu \mathrm{E} \mathrm{m} \mathrm{m}^{-2} \mathrm{~s}^{-1}$. Room mean temperature was $25.5^{\circ} \mathrm{C}$, with a range of 23.9 to $27.8^{\circ} \mathrm{C}$ through the course of these experiments. Soil was watered to saturation after planting and maintained at near field capacity throughout the study.

Disease ratings. Plants were rated for SDS foliar symptoms 24 days after inoculation. Entries were rated if two or more seed emerged. An assessment of each entry was made using a visual disease rating based on a 1-to-9 scale (14), where $1=$ no symptoms, 2 to $4=$ light symptom development ( 1 to $20 \%$ foliage affected), 5 and $6=$ moderate symptom development (20 to $50 \%$ foliage affected), 7 and $8=$ heavy symptom development (50 to $80 \%$ foliage affected), and $9=$ severe symptom development ( 81 to $100 \%$ foliage affected). In all replicated experiments, disease severity ratings were converted to percent foliage affected midpoint values (2).

Experiment set-up. For each experiment, five seed per entry were planted. Each flat contained 20 entries and a moderately resistant (MR) or susceptible
(S) check. The S check was Great Lakes 3302 (GL3302), and the moderately resistant (MR) checks were PI 520733 and PI 567374 (5). The cultivar tests initially were divided into six separate nonreplicated evaluations, UIUC-1999, SIU1999, UIUC-2000, SIU-2000, UIUC-2001, and SIU-2001. Based on the results of this first assessment, entries that had a mean disease severity rating 1.0 standard deviation below the mean for the severity rating were advanced to the second stage. In the second stage, 142 entries in 1999 (from UIUC-1999 and SIU-1999), 74 entries in 2000 (from UIUC-2000 and SIU2000), and 164 entries in 2001 (from UIUC-2001 and SIU-2001) were included. The entries were compared to the checks PI 520733, PI 567374, and GL3302. The entries were arranged in a randomized complete block (RCB) design with four replications. Within each year, the entries with severity ratings statistically lower than the S check GL3302 were advanced to the third stage. These entries, as well as the checks, were re-evaluated using the same methods as previously described. For each third stage, the entries were arranged in an RCB design with four replications and the experiments were repeated.

The ancestral and pedigree sets were inoculated with $F$. solani $\mathrm{f}$. sp. glycines in the greenhouse using the previously described

Table 1. Analysis of variance for sudden death syndrome severity ratings of soybean lines inoculated with Fusarium solani f. sp. glycines in replicated trials in the greenhouse

\begin{tabular}{lrrr}
\hline Source of variation & df & MS & $\boldsymbol{P}>\boldsymbol{F}$ \\
\hline${\text { Stage } 3(1999)^{\mathrm{a}}}^{\mathrm{a}}$ & 1 & 194 & 0.7244 \\
Trial & 4 & 2,221 & 0.2282 \\
Block (trial) & 40 & 9,142 & $<0.0001$ \\
Entry & 40 & 1,182 & 0.8483 \\
Entry $\times$ trial & & & \\
Stage $3(2000)^{\mathrm{b}}$ & 1 & 4,603 & 0.1859 \\
Trial & 4 & 2,778 & 0.3813 \\
Block (trial) & 22 & $2,247,458$ & $<0.0001$ \\
Entry & 22 & 8,777 & 0.9970 \\
Entry $\times$ trial & & & \\
Stage $3(2001)^{\mathrm{c}}$ & 1 & 241 & 0.6498 \\
Trial & 4 & 1,631 & 0.2378 \\
Block (trial) & 23 & 12,660 & 0.0001 \\
Entry & 23 & 298 & 0.9988 \\
Entry $\times$ trial & & & $<0.0001$ \\
Ancestral study & & 8,341 & 0.0010 \\
Trial & 2 & 977 & $<0.0001$ \\
Block (trial) & 6 & 783 & 0.2624 \\
Entry & 93 & 277 & \\
Entry $\times$ trial & 186 & & 0.4402 \\
Pedigree studye & & 161 & 0.0135 \\
Trial & 1 & 783 & 0.0001 \\
Block (trial) & 4 & 1,044 & 0.1166 \\
Entry & 58 & 326 & \\
Entry $\times$ trial & 58 & &
\end{tabular}

${ }^{a}$ In this study, 38 soybean cultivars and three checks were arranged in a randomized complete block design (RCBD) with four blocks. The experiment was repeated.

${ }^{\mathrm{b}}$ In this study, 20 soybean cultivars and three checks were arranged in an RCBD with four blocks. The experiment was repeated.

${ }^{\mathrm{c}}$ In this study, 21 soybean cultivars and three checks were arranged in an RCBD with four blocks. The experiment was repeated.

${ }^{\mathrm{d}}$ In this study, 90 soybean lines and four checks were arranged in an RCBD with three blocks. The experiment was done three times.

${ }^{\mathrm{e}}$ In this study, 55 soybean lines and four checks were arranged in an RCBD with four blocks. The experiment was repeated. method. The S checks were Pioneer P9363 and GL3302 and the MR checks were PI 520733 and PI 567374. Ancestral lines and pedigree lines were arranged in an RCB design with three replications. The ancestral set was evaluated three times and the pedigree set was evaluated twice.

Data analysis. For all replicated experiments, data were subjected to analysis of variance with the general linear models procedure (PROC GLM) of SAS (SAS Institute Inc., Cary, NC). Trials and replications were considered random variables, while entries were considered a fixed variable. Means were separated by Fisher's protected least significant differences (LSD) at $P<0.05$.

\section{RESULTS}

Cultivars. Among the six subsets initially screened, the mean disease severity rating was $57 \%$, compared with ratings of $71 \%$ for GL3302, 29\% for PI 520733, and $24 \%$ for PI 567374 . Of the six subsets, the lowest average rating was $47 \%$ and the highest average rating was $62 \%$. In 1999 , 2000, and 2001 second-stage subsets, the average ratings were 51,47 , and $49 \%$, respectively. For each of the replicated stage three studies from 1999, 2000, and 2001, the cultivar-trial interaction was not significant (Table 1), so the trials were combined. Of the 2,335 cultivars screened in the greenhouse from the six separate subsets, 38 cultivars were identified as MR (Table 2). For an entry to be identified as $\mathrm{MR}$, the disease severity rating was not significantly different from values for both MR checks. Of the two MR checks, PI 567374 had less foliar symptom severity than PI 520733 in most of the experiments. Of the 38 entries identified as MR, five had significantly less disease than PI 520733, while none of the cultivars had significantly less disease than PI 567374. Over half of the entries (54\%) evaluated have the Roundup Ready (RR) gene. Of the 38 MR entries, 14 have the RR gene, while 24 of the entries are conventional (non-RR; Table 2). There was no significant difference in foliar symptoms between the RR and conventional entries within each maturity group (Table 3). However, there was a trend among maturity groups, with the earlier maturing entries having less foliar symptoms than the later maturing entries (Table 3).

Ancestral lines. Although there was a significant difference in severity ratings $(P$ $<0.0001$ ) between trials, data from the three trials were combined and analyzed together because there was not a significant entry-trial interaction for foliar disease severity ratings (Table 1). The mean disease severity rating 24 days after inoculation for GL3302, P9363, PI 520733, and PI 567374 was $73,69,30$, and $24 \%$, respectively. Nine ancestral lines (Aoda, Jackson, Kim, Mammoth Yellow, Sioux, T117, PI 54615-1, PI 71506, and PI 
171450) had severity ratings between 34 and $44 \%$, which were not significantly different $(P<0.05)$ from PI 520733 and were classified as MR (Table 4). The rest of the ancestral set had severity ratings ranging from 45 to $72 \%$. Of the 90 ancestral lines tested, $64 \%$ were not significantly different from the S check and only $10 \%$ were not significantly different from the MR checks. Of the 36 ancestral lines that contribute approximately $95 \%$ of the genes to current cultivars (3), 26 (72\%) were not significantly different from both $\mathrm{S}$ checks and only $2(5 \%)$ were not significantly different from both MR checks.

Lines in the pedigrees of known MR cultivars. Data from the two trials were combined and analyzed together because there was not a significant entry-trial interaction for foliar severity ratings (Table 1). Of the 10 lines evaluated that previously had been reported as MR, only four (Ina, D83-3349, LN98-4340, and LN83-2356) were not significantly different from PI 520733 (the MR check with the highest severity rating at $26 \%$ ), but only Ina and LN98-4340 were not significantly different from PI 567374 (16\%; Table 5). The other six lines were significantly different from the S check GL3302 (68\%; Table 5). In addition to the 4 lines cited above, there were 12 entries with severity ratings not significantly different from PI 520733, 4 ancestral lines and 8 cultivars or experimental lines (Table 5). Three of the four ancestral lines (Jackson, S-100, and Illini) identified as MR in this test also had been tested with the ancestral lines. In the ancestral test, Jackson was not significantly different from the MR checks; Illini was significantly different from all of the $S$ and MR checks, but S-100 was highly susceptible. PI 54610 was included in this test but not in the ancestral set. This PI is in the pedigrees of many cultivars, especially in the southern United States, but the original accession was heterogeneous. The USDA Soybean Germplasm Collection has three sublines of this accession but it is not clear which, if any, of these sublines actually was used as the original parent. Gizlice et al. (3) determined that all of the genetic contribution of PI 54610 was made through Jackson and Ogden; therefore, those lines were included in the ancestral set. Ogden was found to be susceptible.

Bedford, Calland, Cutler, Evans, Harosoy, Hartwig, Hill, and Merit were not significantly different from one of the MR checks. We examined the reactions of each of the progenitors of these lines as well as the 10 lines previously identified as MR in an attempt to identify any consistent sources of resistance in these pedigrees (Table 5). The parents of Harosoy are Mandarin (Ottawa) and A.K. (Harrow), which are both highly susceptible. We know that resistance to SDS is genetically complex (8), so this result is genetically possible. Merit, developed a few years after Harosoy in 1959, was not significantly different from two (Capitol and Mukden) of its three ancestors or the MR checks, but all of its progenitors were. Evans is the progeny of Merit and Harosoy. The four most recently developed

lines with reported levels of moderate resistance (Ina, LN83-2356, LN92-7369, and LN98-4340) all have both PI 54610 and S-100 as ancestors. In addition, they have between three and five cultivars that we have identified as MR as progenitors

Table 2. List of 38 soybean cultivars identified as moderately resistant to sudden death syndrome in the greenhouse

\begin{tabular}{|c|c|c|c|}
\hline Entry $^{a}$ & Seed source $^{b}$ & Maturity group & $\mathrm{CV} / \mathbf{R R}^{\mathrm{c}}$ \\
\hline Agrisoy 2512 & Agrinetics & II & $\mathrm{CV}$ \\
\hline $4900 \mathrm{RR}$ & Baker & IV & $\mathrm{RR}$ \\
\hline BT $480 \mathrm{R}$ & Bergmann-Taylor & IV & $\mathrm{RR}$ \\
\hline Midland 9B 480 RR & Brown & IV & $\mathrm{RR}$ \\
\hline 9474 & Callahan & IV & $\mathrm{CV}$ \\
\hline DST 2336 RR & Dairyland Seed Co. & II & $\mathrm{RR}$ \\
\hline $4885 \mathrm{RR}$ & Delta \& Pine land & IV & $\mathrm{RR}$ \\
\hline DPX 8545 RR & Delta \& Pine land & IV & $\mathrm{RR}$ \\
\hline DPX 8547 RR & Delta \& Pine land & IV & $\mathrm{RR}$ \\
\hline D240C & Diener Seeds & II & $\mathrm{CV}$ \\
\hline 8333 NRR & Excel & III & $\mathrm{RR}$ \\
\hline D 246 STS & Garst Seed Co. & II & $\mathrm{CV}$ \\
\hline D 478 & Garst Seed Co. & IV & $\mathrm{CV}$ \\
\hline IA 3010 & Iowa State Univ. & III & $\mathrm{CV}$ \\
\hline $3592 \mathrm{RR}$ & Lewis & III & $\mathrm{RR}$ \\
\hline C $1828 \mathrm{RR}$ & LG Seeds & I & $\mathrm{RR}$ \\
\hline MRK 9927 RR & Mark & II & $\mathrm{RR}$ \\
\hline SC Solomon & Miles & III & $\mathrm{RR}$ \\
\hline HS 96-332 & Ohio State Univ. & II & $\mathrm{CV}$ \\
\hline SD 95-789 & South Dakota State University & I & $\mathrm{CV}$ \\
\hline SD 96-1043 & South Dakota State University & II & $\mathrm{CV}$ \\
\hline Papasan & Specialty Grains & II & $\mathrm{CV}$ \\
\hline $3101 \mathrm{RR}$ & Strike & III & $\mathrm{RR}$ \\
\hline DG 3395 & UAP & III & $\mathrm{CV}$ \\
\hline DG 3399 & UAP & III & $\mathrm{RR}$ \\
\hline R 96-3235 & University of Arkansas & IV & $\mathrm{CV}$ \\
\hline Ina & University of Illinois & IV & $\mathrm{CV}$ \\
\hline LN 83-2356 & University of Illinois & IV & $\mathrm{CV}$ \\
\hline LN 92-7369 & University of Illinois & II & $\mathrm{CV}$ \\
\hline LN 94-15292-97 & University of Illinois & II & $\mathrm{CV}$ \\
\hline LN 95-6415 & University of Illinois & III & $\mathrm{CV}$ \\
\hline LN 97-14868 & University of Illinois & III & $\mathrm{CV}$ \\
\hline LN 98-4340 & University of Illinois & II & $\mathrm{CV}$ \\
\hline M 92-1731 & University of Minnesota & II & $\mathrm{CV}$ \\
\hline MN 0901 & University of Minnesota & I & $\mathrm{CV}$ \\
\hline MN 1401 & University of Minnesota & I & $\mathrm{CV}$ \\
\hline Parker & University of Minnesota & I & $\mathrm{CV}$ \\
\hline U 97-2406 & University of Nebraska & II & $\mathrm{CV}$ \\
\hline GL3302 & CHECK (S) & III & $\mathrm{CV}$ \\
\hline PI 520733 & CHECK (MR) & III & $\mathrm{CV}$ \\
\hline PI 567374 & CHECK (MR) & IV & $\mathrm{CV}$ \\
\hline
\end{tabular}

${ }^{a}$ Moderately resistant cultivars were identified by the final foliar rating as being not significantly $(P$ $<0.05$ ) different than either of the moderately resistant checks (PI 520733 and PI 567374).

${ }^{\text {b }}$ Checks: $\mathrm{S}=$ susceptible to Fusarium solani f. sp. glycines and MR = moderately resistant.

${ }^{\mathrm{c}} \mathrm{CV}=$ conventional cultivar and $\mathrm{RR}=$ Roundup Ready cultivar.

Table 3. Mean foliar ratings for sudden death syndrome of Roundup Ready and conventional cultivars after inoculation in the greenhouse ${ }^{\mathrm{a}}$

\begin{tabular}{lcclcc}
\hline & \multicolumn{2}{c}{ Roundup Ready } & & \multicolumn{2}{c}{ Conventional } \\
\cline { 2 - 3 } \cline { 5 - 6 } Maturity group $^{\mathbf{b}}$ & No. cultivars & Severity rating (\%) & & No. cultivars & Severity rating (\%) \\
\hline I & 25 & 48 & & 82 & 45 \\
II & 367 & 51 & & 298 & 50 \\
III & 399 & 54 & & 263 & 52 \\
IV & 159 & 54 & & 137 & 53 \\
V & 22 & 54 & & 59 & 57 \\
LSD $(0.05)$ & $\ldots$ & 6 & & $\ldots$ & 4 \\
\hline
\end{tabular}

a Cultivars from the UIUC-1999, SIU-1999, UIUC-2000, SIU-2000, UIUC-2001, and SIU-2001 studies. Herbicide resistance information on approximately 500 cultivars was unknown and, therefore, not included in the analysis. Disease ratings were based on a 1-to-9 scale (14), where $1=$ no symptoms and $9=$ severe symptom development. Data were converted to midpoint values (5) based on range within each severity rating scale.

${ }^{\mathrm{b}}$ LSD $=$ Fisher's protected least significant difference; no significant difference between Roundup Ready and conventional cultivars. 
(Table 5). S-100 is in the pedigree of all of the MR cultivars or experimental lines in maturity groups $\mathrm{V}$ and later (Bedford, Hartwig, Hill, Forrest, and D83-3349). S100 is a very prominent ancestor in these maturity groups; therefore, we cannot be sure of the significance of this common

Table 4. Mean sudden death syndrome disease severity ratings (DSRs) of soybean ancestral lines rated as moderately resistant, as well as moderately resistant and susceptible checks in replicated greenhouse experiments after inoculation with Fusarium solani f. sp. glycines

\begin{tabular}{lcc}
\hline Entry $^{\mathbf{a}}$ & $\begin{array}{c}\text { Maturity } \\
\text { group }\end{array}$ & $\begin{array}{c}\text { DSR } \\
(\boldsymbol{\%})^{\mathbf{b}}\end{array}$ \\
\hline Jackson & VII & 44 \\
PI 71506 & IV & 44 \\
Mammoth Yellow & VII & 43 \\
Sioux & 000 & 43 \\
T117 & IV & 43 \\
PI 54615-1 & III & 42 \\
PI 171450 & III & 41 \\
Aoda & IV & 35 \\
Kim & III & 34 \\
GL3302 (S) & III & 69 \\
Pioneer P9363 (S) & III & 73 \\
PI 520733 (MR) & III & 30 \\
PI 567374 (MR) & IV & 24 \\
LSD (0.05) & $\ldots$ & 14 \\
\hline
\end{tabular}

${ }^{a} \mathrm{~S}=$ susceptible to $F$. solani $\mathrm{f}$. sp. glycines and $\mathrm{MR}=$ moderately resistant; LSD = Fisher's protected least significant difference.

${ }^{b}$ Disease ratings were based on a 1-to-9 scale (14), where $1=$ no symptoms and $9=$ severe symptom development. Data were converted to midpoint values (5) based on range within each severity rating scale. occurrence. The only MR ancestor in the pedigree of Hill is S-100, and all of the MR southern lines developed since Hill have Hill as an ancestor.

The six lines not shown to be MR in this research, but previously identified as such, have pedigrees similar to those of the cultivars rated as MR in this study (Table 5). Forrest is a progenitor of Ina and its ancestry includes Hill, Jackson, and S-100. The Burlison pedigree includes Harosoy, Hill, S-100, and PI 54610. LN92-7369 has Burlison and Calland in its pedigree. The ancestry of Bell includes Calland and Harosoy. The pedigree of Jack includes Harosoy, Cutler, and PI 54610. Ripley is the only entry in this study with PI 71506, which was MR in the ancestral study (Table 4), in its pedigree, but also includes PI 54610.

\section{DISCUSSION}

In this study, 2,335 cultivars and experimental lines were screened over a 3-year period in the greenhouse. Less than $2 \%$ were considered MR when compared with PI 520733 and only five $(0.2 \%)$ were not different from PI 567374. Although most of the entries in this study were susceptible to the aggressive isolate Mont-1 (4,15), there are at least a few that were not and these may be of use in breeding programs, genetic studies, and for soybean growers that persistently have SDS in their fields.

Farmers and trade journals have raised concerns about increased SDS severity in RR soybean cultivars. Our experimental data did not indicate that RR cultivars are more susceptible to $F$. solani f. sp. glycines than conventional cultivars within each maturity group. Previous research has indicated that RR and conventional cultivars responded similarly to infection of $F$. solani f. sp. glycines after different herbicide applications $(19,20)$. Although no differences were found between RR cultivars and conventional cultivars, there were differences in disease severity among entries in different maturity groups. There was a trend for earlier-maturing entries to have less foliar symptoms than later-maturing entries. This was true for both RR and conventional cultivars. However, these data were calculated from the foliar ratings in the nonreplicated trials, and the number of observations within each maturity group varies.

Screening the ancestral set can provide an indication of the level of resistance possible in current cultivars. Bradley et al. (1) identified 21 ancestral lines with resistance to Rhizoctonia solani. Most of the nine ancestral lines identified as MR to SDS in this study made very little contribution to current cultivars. Aoda and Kim are large-seeded lines and are not in the pedigrees of any current commodity cultivars (3). PI 54615-1, PI 171450, T117, Mammoth Yellow, and Sioux were used as donor parents in backcrossing or were otherwise very minor contributors and occur in the pedigrees of very few current cultivars (3). PI 71506 is a progenitor of Ripley and Jackson is one of the major

Table 5. Selected soybean entries and sudden death syndrome disease severity ratings after greenhouse inoculation with Mont- 1 strain of the pathogen ${ }^{\mathrm{a}}$

\begin{tabular}{lccl}
\hline Entry & Maturity group & Disease severity rating $\mathbf{( \% )}^{\mathbf{b}}$ & \multicolumn{1}{c}{ Moderately resistant progenitors in the pedigree } \\
\hline PI 567374 & IV & 16 & $\ldots$ \\
PI 520733 & III & 26 & $\ldots$ \\
Ina & IV & 27 & Cutler, Forrest, Harosoy, Hartwig, Hill, Jackson, PI 54610, S-100 \\
Hartwig & V & 30 & Forrest, Hill, Jackson, PI 54610, S-100 \\
LN 98-4340 & II & 32 & Calland, Cutler, Harosoy, Hill, PI 54610, S-100 \\
PI 54610 & VI & 32 & $\ldots$ \\
LN 83-2356 & IV & 39 & Calland, Evans, Harosoy, Merit, PI 54610, S-100 \\
D83-3349 & IV & 41 & Bedford, Forrest, Hill, S-100 \\
Harosoy & II & 41 & $\ldots$ \\
Bedford & V & 42 & Forrest, Hill, S-100 \\
Merit & 0 & 43 & $\ldots$ \\
Jackson & VII & 43 & PI 54610 \\
S-100 & V & 43 & $\ldots$ \\
Calland & III & 43 & Harosoy, PI 54610 \\
Cutler & IV & 43 & PI 54610 \\
Hill & V & 43 & S-100 \\
Illini & IV & $\ldots$ \\
Evans & O & 44 & Harosoy, Merit \\
Forrest & V & 46 & Hill, Jackson, PI 54610, S-100 \\
LN 92-7369 & II & Calland Harosoy, Hill, PI 54610, S-100 \\
Bell & I & 50 & Calland, Harosoy \\
Burlison & II & Calland, Harosoy, Hill, PI 54610, S-100 \\
Ripley & IV & 50 & PI 71506, PI 54610 \\
Jack & II & 50 & Cutler, Harosoy, PI 54610 \\
GL3302 & III & $\ldots$ \\
LSD (0.05) & $\ldots$ & 68 & $\ldots$ \\
\hline
\end{tabular}

a All known moderately resistance progenitors of each entry are included. LSD = Fisher's protected least significant difference.

${ }^{\mathrm{b}}$ Disease ratings were based on a 1 -to 9 -scale $(14)$, where $1=$ no symptoms and $9=$ severe symptom development. Data were converted to midpoint values (5) based on range within each severity rating scale.

${ }^{c}$ The original PI 54610 was heterogeneous. This is one of three sublines maintained in the USDA National Soybean Germplasm Collection but we do not know which, if any, of these genotypes was the actual ancestral line. 
U.S. ancestral line that is in the pedigrees of Ina, Hartwig, and Forrest; therefore, the resistance in these ancestral lines may be important in current production. In this research, PI 54610 was among the most resistant lines tested and is in the pedigree of more than half of the MR lines found in this research or previously reported. We are not sure that this particular genotype actually was used as the original parent, and PI 54610 is a very common ancestor for U.S. cultivars; therefore, we cannot be sure of the significance of this high percentage but it may be an important contributor to resistance expressed in current cultivars.

The erratic behavior of S-100 requires additional investigation. Rating differences for the same entry between trials is common, but only S-100 displayed the extremes of both MR and highly susceptible in different tests.

Most of the 36 ancestral soybean lines that represent approximately $95 \%$ of the genes in current North American soybean cultivars (3) are susceptible, but our results indicate that MR progeny can be produced from $\mathrm{S}$ parents. Although not a recommended strategy for increasing disease resistance, it is consistent with a quantitative genetic model (8). The sources of resistance in Harosoy and Merit are not obvious, but the fact that MR Evans is a progeny of these two lines is evidence that the resistance is real. Of the 15 cultivars and experiment lines in maturity groups IV and earlier that we found or have been previously reported to be MR to SDS, Harosoy is in the pedigree of 10. Harosoy was used widely as a parent; therefore, a high percentage of cultivars are likely to include it as an ancestor. Selection for improved SDS resistance within the currently used gene pool may increase the level of resistance, especially if putative sources of resistance can be combined.

None of the cultivars or ancestral or experimental lines exhibited higher levels of resistance than PI 567374. Continued screening of plant introductions from the USDA Soybean Germplasm Collection is needed and new sources of resistance need to be included in cultivar development.
More research also is needed to identify an improved technique for screening SDS resistance in the field, which would allow for more accurate comparisons of greenhouse and field evaluations.

\section{ACKNOWLEDGMENTS}

We thank K. Ames, C. Bradley, C. Kleinschmidt, C. Leman, S. Li, D. Mueller, J. Mueller, R. Warsaw, and C. Weeks for their assistance.

\section{LITERATURE CITED}

1. Bradley, C. A., Hartman, G. L., Nelson, R. L., Mueller, D. S., and Pedersen, W. L. 2001. Response of ancestral soybean lines and commercial cultivars to Rhizoctonia root and hypocotyl rot. Plant Dis. 85:1091-1095.

2. Campbell, C. L., and Madden, L. V. 1990. Introduction to Plant Epidemiology. John Wiley \& Sons, New York.

3. Gizlice, Z., Carter, T. E., and Burton, J. W. 1994. Genetic base for North American public soybean cultivars released between 1947 and 1988. Crop Sci. 34:1143-1151.

4. Gray, L. E., and Achenbach, L. A. 1996. Severity of foliar symptoms and root and crown rot of soybean inoculated with various isolates and inoculum rates of Fusarium solani. Plant Dis. 80:1197-1199.

5. Hartman, G. L., Huang, Y. H., Nelson, R. L., and Noel, G. R. 1997. Germplasm evaluation of Glycine max for resistance to Fusarium solani, the causal organism of sudden death syndrome. Plant Dis. 81:515-518.

6. Hartman, G. L., Noel, G. R., and Gray, L. E. 1995. Occurrence of soybean sudden death syndrome in east-central Illinois and associated yield losses. Plant Dis. 79:314-318.

7. Hartwig, E. E., Young, L. D., and Gibson, P. 1996. Registration of soybean germplasm line D83-3349 resistant to sudden death syndrome, soybean cyst nematode, and two root-knot nematodes. Crop Sci. 36:212.

8. Hnetkovsky, N., Chang, S. J. C., Doubler, T. W., Gibson, P. T., and Lightfoot, D. A. 1996. Genetic mapping of loci underlying field resistance to soybean sudden death syndrome (SDS). Crop Sci. 36:393-400.

9. Huang, Y. H., and Hartman, G. L. 1998. Reaction of selected soybean genotypes to isolates of Fusarium solani f. sp. glycines and their culture filtrates. Plant Dis. 82:999-1002.

10. Jin, H., Hartman, G. L., Nickell, C. D., and Widholm, J. M. 1996. Phytotoxicity of culture filtrate from Fusarium solani, the causal agent of sudden death syndrome of soybean. Plant Dis. 80:922-927.

11. Killebrew, J. F., Roy, K. W., Lawrence, G. W., McLean, K. S., and Hodges, H. H. 1988. Greenhouse and field evaluation of Fusarium solani pathogenicity to soybean seedlings. Plant Dis. 72:1067-1070.
12. Luo, Y., Myers, O., Lightfoot, D. A., and Schmidt, M. E. 1999. Root colonization of soybean cultivars in the field by Fusarium solani f. sp. glycines. Plant Dis. 83:11551159.

13. Melgar, J., and Roy, K. W. 1994. Soybean sudden death syndrome: Cultivar reactions to inoculation in a controlled environment and host range and virulence of causal agent. Plant Dis. 78:265-268.

14. Mueller, D. S., Hartman, G. L., Nelson, R. L., and Pedersen, W. L. 2002. Evaluation of Glycine max germ plasm for resistance to Fusarium solani f. sp. glycines. Plant Dis. 86:741746.

15. Mueller, D. S., Nelson, R. L., Hartman, G. L., Bradley, C. A., and Pedersen, W. L. 2000. Evaluation of ancestral soybean lines for resistance to Fusarium solani f. sp. glycines. Page 97 in: Agronomy Abstracts. ASA, Madison, WI

16. Roy, K. W., Rupe, J. C., Hershman, D. E., and Abney, T. S. 1997. Sudden death syndrome of soybean. Plant Dis. 81:1100-1111.

17. Rupe, J. C. 1989. Frequency and pathogenicity of Fusarium solani recovered from soybeans with sudden death syndrome. Plant Dis. 73:581-584.

18. Rupe, J. C., Gbur, E. E., and Marx D. M. 1991. Cultivar responses to sudden death syndrome of soybean. Plant Dis. 75:47-50.

19. Sanogo, S. Yang, X. B., and Lundeen, P. 2001. Field response of glyphosate-tolerant soybean to herbicides and sudden death syndrome. Plant Dis. 85:773-779.

20. Sanogo, S., Yang, X. B., and Scherm, H. 2000. Effects of herbicides on Fusarium solani f. sp. glycines and development of sudden death syndrome in glyphosate-tolerant soybean. Phytopathology 90:57-66.

21. Stephens, P. A. 1992. Expression and inheritance of resistance to Fusarium solani in soybean. Ph.D. dissertation. University of Illinois, Urbana-Champaign.

22. Stephens, P. A., Nickell, C. D., and Kolb, F. L. 1993. Genetic analysis of resistance to Fusarium solani in soybean. Crop Sci. 33:929-930.

23. Stephens, P. A., Nickell, C. D., and Lim, S. M. 1993. Sudden death syndrome development in soybean cultivars differing in resistance to Fusarium solani. Crop Sci. 33:63-66.

24. Stephens, P. A., Nickell, C. D., Moots, C. K., and Lim, S. M. 1993. Relationship between field and greenhouse reactions of soybean to Fusarium solani. Plant Dis. 77:163-166.

25. Wrather, J. A., Stienstra, W. C., and Koenning, S. R. 2001. Soybean disease loss estimates for the United States from 1996 to 1998. Can. J. Plant Pathol. 23:122-131.

26. Yang, X. B., and Lundeen, P. 1997. Occurrence and distribution of soybean sudden death syndrome in Iowa. Plant Dis. 81:719722 . 